1 Article

\title{
2 Love bites - Do venomous arachnids make safe pets?
}

\author{
3 Tobias J. Hauke ${ }^{1, *}$, and Volker Herzig $2, \neq, * *$ \\ 41 Munich, 81377, Germany; t.hauke87@googlemail.com \\ 52 GeneCology Research Centre, School of Science, Technology and Engineering, University of the Sunshine \\ $6 \quad$ Coast, Sippy Downs, QLD 4556, Australia; vherzig@usc.edu.au \\ 7 * Correspondence: vherzig@usc.edu.au; Tel.: +61-7-5456-5382 \\ $8 \quad$ * Equal contribution
}

9

\section{Abstract:}

With a global estimate of tens of thousands of arachnid enthusiasts, spiders and scorpions are gaining increasing popularity as pets in industrialised countries in Europe, Northern America and Asia. As most spiders and all scorpions are venomous and due to their mostly negative image in the public media, several governments are already considering introducing legislation to regulate the domestic care of potentially dangerous captive animals. We aimed to investigate the circumstances and effects of exposure to arachnids kept in captivity. Thus, we collected and analysed data from 354 selfreported bites and stings attributed to pet arachnids. Our data revealed that on average there were less than 20 recorded envenomations per year with $\sim 90 \%$ preventable by due care. We also categorized the severity of the resulting symptoms and found that the vast majority of symptoms were either local $(60.7 \%)$ or minor $(32.8 \%), 5.4 \%$ were asymptomatic, only $1.1 \%$ were severe and no fatalities were recorded. Based on our database of bite and sting reports, we performed a risk assessment for arachnid pet ownership and concluded that, with the proper care, arachnids can be safely kept as pets and pose a lower risk than many other recreational activities.

24 Keywords: Spider; Scorpion; Pet; Bite; Sting; Envenomation

\section{Abbreviations}

BTS = British Tarantula Society

DeArGe = Deutsche Arachnologische Gesellschaft e.V. 


\section{Introduction}

Despite their fearsome reputation in public media (Mammola et al., 2020), venomous arachnids such as spiders and scorpions have gained increasing popularity as pets in recent decades in some industrialised countries in Europe, Northern America and Asia. The continuously increasing demand for new arachnid pet species has wide-ranging implications including illegal trading (Fukushima et al., 2020; Law, 2019). On the other hand, arachnid pets also offer a diverse and easily accessible resource for research in various disciplines associated with arachnids, such as taxonomy (Montemor et al., 2020; Nunn et al., 2016), toxinology (Bibic et al., 2019; Klint et al., 2015), biodiversity (Huesser, 2018), protection of endangered species (Kroes and Maerklin, 2014), physiology (Foelix et al., 2009; Foelix et al., 2012) and evolution (Foley et al., 2019; Lueddecke et al., 2018). In addition to arachnids, other venomous animals such as centipedes or snakes are also becoming increasingly popular as pets and Europe is considered a global hot spot in regard to exotic pets (Fukushima et al., 2020; Law, 2019). A recent case of an escaped pet cobra (Naja kaouthia) that was on the loose for several days in Herne (Germany) before finally being caught safely (Aachener Zeitung, 2019) has caused public concerns about the suitability of venomous animals as pets. This has for example prompted the local government of North-Rhine Westphalia (Germany) to consider introducing regulations to control or restrict keeping potentially dangerous animals in captivity, including venomous arachnids (Aachener Zeitung, 2020). Other German states (Bayrische Staatskanzlei, 2015; Regierungspräsidium Kassel, 2007) and countries such as Italy (Parlamento Italiano, 2003) or the UK (UK Government, 1976) have previously introduced similar legislation. And further countries might also come to a point where they see the need to regulate venomous animals in captivity. Unfortunately, the responsible regulatory agencies rarely have the scientific expertise to judge which species should be considered as potentially dangerous. Therefore, we already provided our expert reports to three German states (Bavaria, Hesse, and North-Rhine Westphalia) and to a wider audience (Hauke and Herzig, 2017).

Our previous review article was mostly focused on assessing the potential danger of arachnids based on bites or stings that occurred in their respective countries of origin (Hauke and Herzig, 2017). For authorities to make sensible decisions about pet arachnids, they first need to understand the specific risks associated with arachnids held in captivity. By performing a global search for case reports in online forums and popular magazines dealing with pet arachnids and by distributing a questionnaire about such cases to pet owners in Europe and Northern America, we have compiled a large database of 354 self-reported bites or stings from pet arachnids. This database allows us to determine which arachnid genera are involved in these incidents and it also enables us to examine the range of effects resulting from the bites and stings. Comparing the genera responsible for these cases with their respective popularity in the pet scene, also helped to uncover genera which are disproportionately involved. Furthermore, for understanding the severity of each case, we classified the resulting symptoms as asymptomatic, local, minor, or severe. Overall, the analysis of our pet arachnid bite and sting database allowed us to perform a specific risk assessment for keeping arachnids as pets, which might be used as a foundation by authorities to base their future decisions on regulations related to arachnid pets.

\section{Materials and methods}

In order to maximise the number of pet arachnid bite and sting reports to be analysed in this study, we obtained cases from a wide variety of different sources. Therefore, we screened several internet forums as well as other internet resources (Angelfire; Arachnoboards; Arachnophilia; BTS homepage; Facebook; Poeci1; Reptilesworld; SKF - Schattenjaeger im Terrarium; SkorpionForum; The Arachnoholic; Vogelspinnenstammtisch Schweiz) for any reports of pet spider bites or scorpion stings in humans. As search parameters in these online media, we entered terms such as ",bite“, "sting“", ",bitten“, „,stung“, „,envenomation“ (in the respective language of each online medium). In addition, we 
compiled pet arachnid envenomation reports from popular magazines ("Arachne”, "Arachnologischer Anzeiger", and "BTS Journal"). Finally, we prepared a questionnaire (see Supplementary Materials) and distributed it within the European and American arachnid pet scene in order to obtain feedback on arachnid envenomation cases that were caused by pet arachnids. Any cases that contained insufficient details or apparent errors or which reported symptoms unlikely to be caused by the bite/sting itself were excluded during a pre-selection process. All data were then compiled into an excel table (see Supplementary Excel file) for a detailed statistical analysis and to determine symptoms that are particularly prevalent after envenomations by selected arachnid genera. Due to the limited numbers of cases per species, we have restricted our detailed analysis of envenomation symptoms to the genus level.

In order to minimize any diagnosis bias due to potentially incorrect self-diagnoses by the pet owners reporting these cases, we only analysed those symptoms with an average incidence rate of at least $10 \%$ within spiders or scorpions. For the detailed analysis of envenomations by selected arachnid genera (with at least five reported cases), we used a 30\% incidence cut-off rate. Given that there are no records available about how prevalent each arachnid genus is within the arachnid pet scene, we have estimated their popularity based on how frequently they are described in popular books on arachnid husbandry. A list of these books can be found in Table S1. In order to assess the severity of each arachnid envenomation, we introduced a classification scheme with four categories as detailed in Table 1 and which has been adapted from an existing classification for the severity of scorpion envenomations (Khattabi et al., 2011).

Table 1. Scheme used to classify the degree of severity of symptoms associated with each reported pet arachnid bite or sting.

\begin{tabular}{|l|l|}
\hline Classification & Associated symptoms \\
\hline Asymptomatic & No symptoms reported \\
Local & All symptoms remain localized to the bite/sting site \\
Minor & Radiated and/or systemic symptoms (non life-threatening) \\
Severe & Causing potentially life-threatening effects \\
\hline
\end{tabular}

\section{Results}

The present study is based on 354 case reports, which have been sourced from a wide range of media, including internet sources $(84.5 \%)$, popular arachnid magazines $(9.3 \%)$ and replies to our envenomation questionnaire (6.2\%). The great majority of cases relates to spider bites $(83.6 \%)$ with only a minority of scorpion sting cases (16.4\%). The 296 spider bite cases were caused by seven different spider families (Figure 1A) from 47 different genera (Table S2) with the vast majority being caused by spiders of the family Theraphosidae (96.3\%) (Figure 1A). The 58 scorpion sting cases were caused by scorpions from 22 different genera (Table S3) within eight different families (Figure 1B), although the majority of cases were caused by species from the families Buthidae (58.6\%) and Scorpionidae (24.1\%). In those cases where the sex of the envenomating arachnid has been identified, it turned out that mainly female arachnids were responsible $(75.5 \%$ in spiders and $63.6 \%$ in scorpions). Also, a single (rather than multiple) bite/sting occurred in the majority of cases (81.3\% in spiders and $76.5 \%$ in scorpions).

Males are over-represented among the victims of arachnids, accounting for $100 \%$ of scorpion stings and $82.0 \%$ of spider bites. According to the reasons that resulted in the contact with the arachnid, the majority of encounters were due to a deliberate interaction (e.g. maintenance, handling, transferring, or actively induced), whereas only a minority of cases were due to arachnids that had managed to escape or were prevented from trying to escape (Figure 1C). The great majority of bites and stings $(85.0 \%)$ were delivered to the hand, including the fingers (Figure 1D). Only 10.5\% of all arachnid exposures specified that they sought professional help through calling a hotline or visiting 
126

127

128

a doctor or hospital (Figure 1E). The age of the victims of arachnid bites/stings ranged from 12 to 64 years with a median age of 32 (Figure 1F).
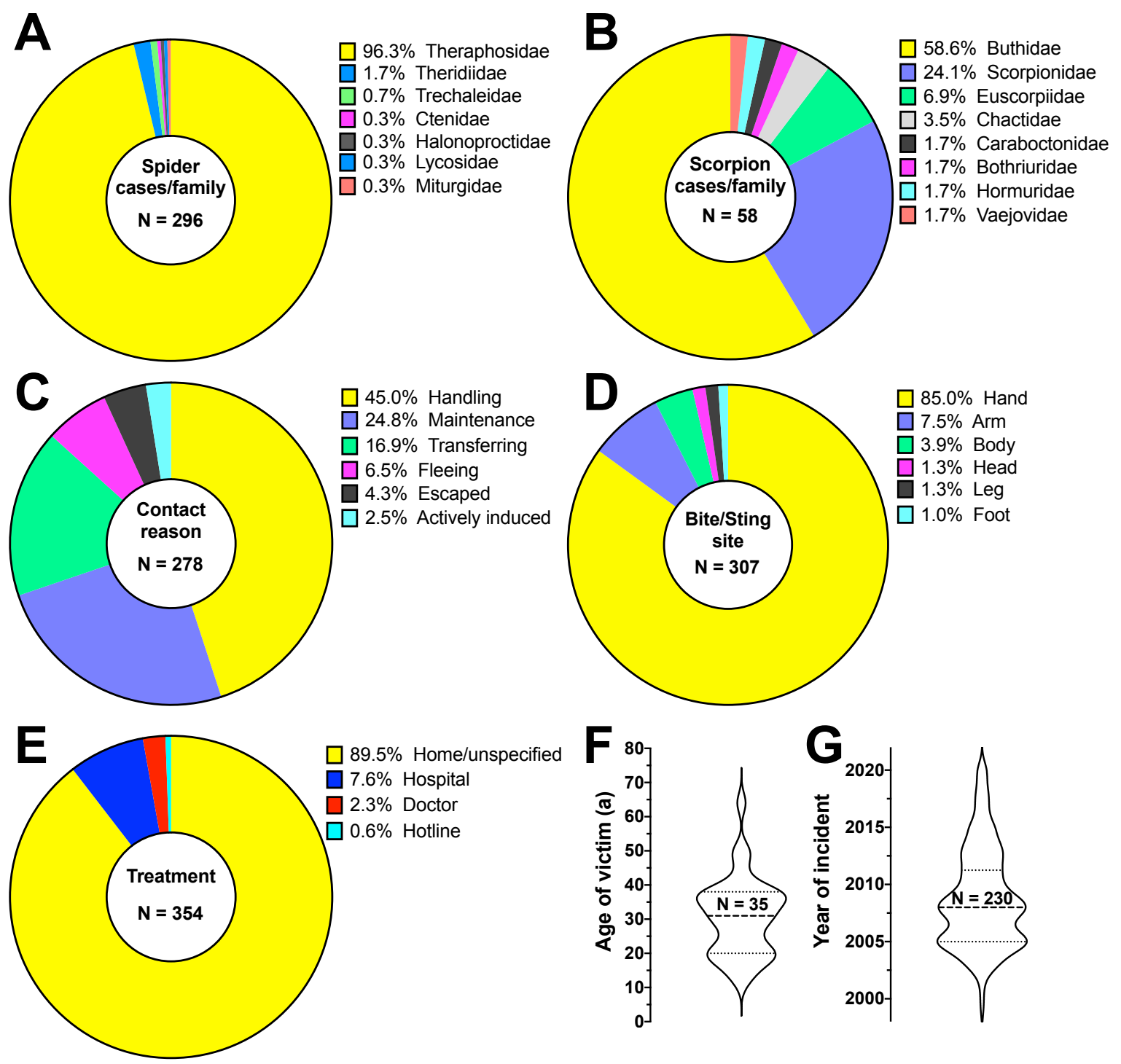

Figure 1. Envenomation statistics. All values are calculated based on those cases (the respective Nnumbers are indicated for each panel) that supplied the particular details. (A) Percental distribution of all 296 recorded spider bite cases across 7 different spider families. (B) Percental distribution of all 58 recorded scorpion sting cases across 8 different scorpion families. (C) Percental distribution of the contact reason with the arachnid. (D) Percental distribution of the bite/sting site in the victim. (E) Percental distribution of the treatment location. (F) Violin plot indicating distribution of the age (in years) of the bite/sting victims. (G) Violin plot indicating the year when the bite/sting occurred. Seven cases occurred prior to 2000 (i.e. 1951, 1979, 1987, 1989, 2x 1990, and 1999) but are not displayed for reasons of simplification. In the violin plots in $(\mathbf{F})$ and $(\mathbf{G})$, the dotted lines represent the $1^{\text {st }}$ and $3^{\text {rd }}$ quartile and the dashed line indicates the median.

We also performed an analysis of the popularity of particular arachnid genera (see Supplementary Excel file) based on how frequently they are mentioned in popular books about the maintenance of arachnids in captivity (Table S1). Then we performed a linear regression comparing the popularity of each genus with the frequency of bites or stings that were caused by that genus in our database (Figure 2). 

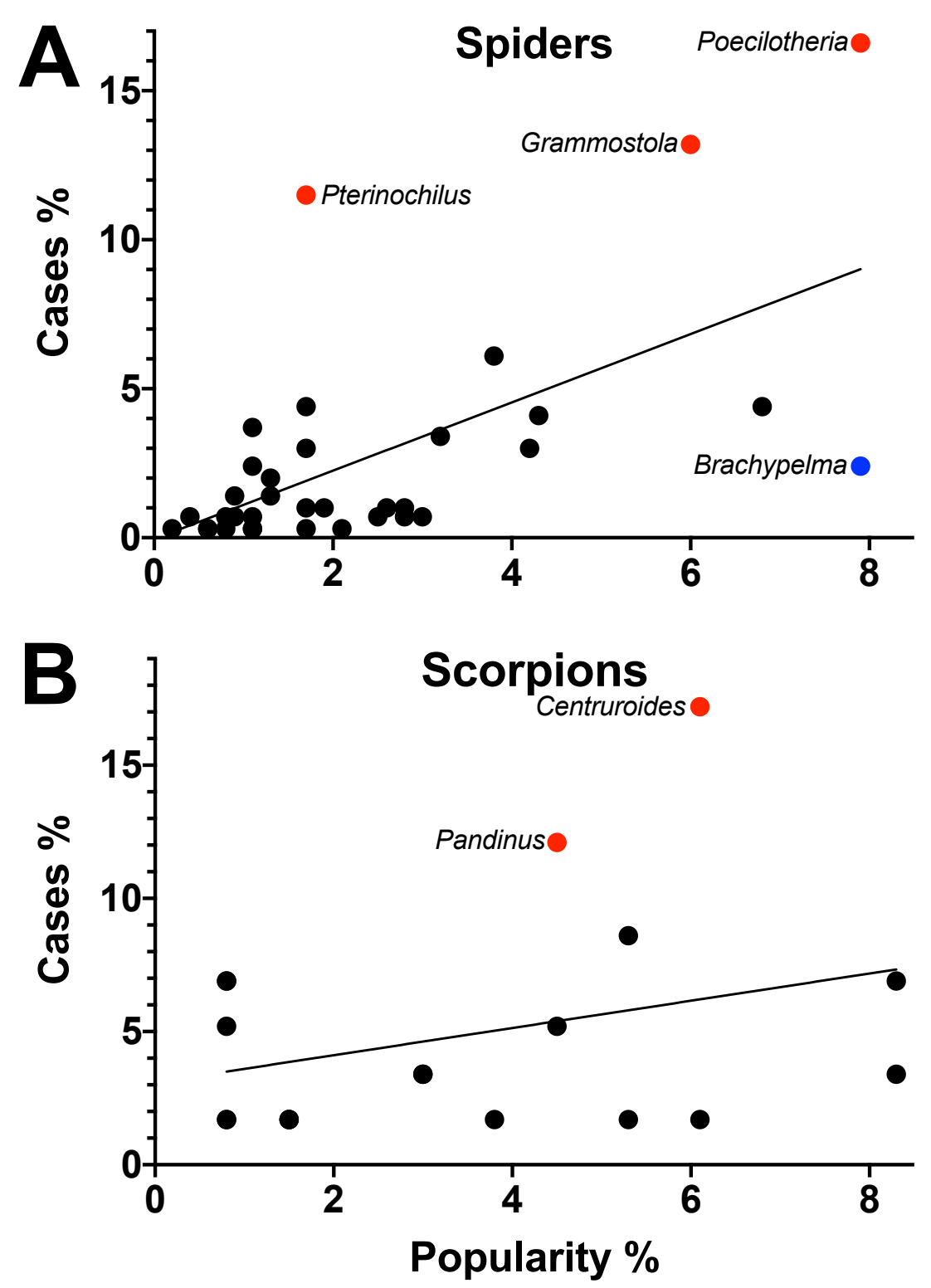

Figure 2. Linear regression for correlation of popularity of (A) spider and (B) scorpion genera with their respective incidence rates for causing bites or stings. Those genera that have a disproportionate incidence rate (as defined by a difference from the linear correlation of at least $5 \%$ ) are indicated by the respective genus name and the data point colored in red for a higher or blue for a lower incidence rate than predicted from their popularity, all other data points are in black.

Based on a first analysis of symptoms with an incidence rate of at least $10 \%$ in one of the arachnid orders (Table 2), the top 5 of the most frequent symptoms after scorpion stings are local pain (86.2\%), numbness $(20.7 \%)$, swelling (19.0), paraesthesia $(17.2 \%)$ and radiating pain $(15.5 \%)$. The top 5 symptoms after spider bites are local pain (79.4\%), swelling (45.3\%), puncture marks (29.1\%), redness $(26.4 \%)$ and muscle cramps (23.0\%). Some symptoms were preferentially caused by spiders (muscle cramps, local bleeding, puncture marks, nausea/vomiting, generalised pain, stiffness, swelling, itching, and redness), whereas other symptoms were more likely experienced after scorpion stings (paraesthesia, numbness, radiating and local pain).

Table 2. Comparison of incidence rates (in \%) of frequent envenomation symptoms (based on $10 \%$ incidence rate in at least one of the arachnid orders and ordered according to an increasing prevalence in spiders) 
165

166

between all reported envenomation cases from scorpions $(\mathrm{N}=58)$ and spiders $(\mathrm{N}=296)$. The symptoms shaded in grey have a higher incidence rate in scorpions, all other symptoms have a higher incidence rate in spiders.

\begin{tabular}{|l|ll|}
\hline Symptoms & Scorpion (\%) & Spider (\%) \\
\hline Paraesthesia & 17.2 & 12.8 \\
Numbness & 20.7 & 15.9 \\
Radiating pain & 15.5 & 13.5 \\
Local pain & 86.2 & 79.4 \\
Redness & 13.8 & 26.4 \\
Itching & 8.6 & 20.3 \\
Swelling & 19.0 & 45.3 \\
Stiffness & 3.4 & 12.5 \\
Generalised pain & 1.7 & 9.5 \\
Nausea/Vomiting & 1.7 & 9.8 \\
Puncture marks & 3.4 & 29.1 \\
Local bleeding & 1.7 & 14.9 \\
Muscle cramps & 0.0 & 23.0 \\
\hline
\end{tabular}

The classification of all 354 case reports based on their degree of severity revealed that the great majority of all cases are either local $(60.7 \%)$ or minor $(32.8 \%)$, with another $5.4 \%$ of asymptomatic and only $1.1 \%$ of severe cases (Table 3 ).

Table 3. Comparison of the percental distribution of severity of symptoms between scorpion stings $(\mathrm{N}=58)$ and spiders bites ( $\mathrm{N}=296)$. The average distribution across all 354 arachnid envenomations is indicated in bold.

\begin{tabular}{|l|lll|}
\hline Symptom severity (\%) & Scorpions & Spiders & Average/354 cases \\
\hline Asymptomatic & 5.2 & 5.4 & $\mathbf{5 . 4}$ \\
Local & 69.0 & 59.1 & $\mathbf{6 0 . 7}$ \\
Minor & 25.9 & 34.1 & $\mathbf{3 2 . 8}$ \\
Severe & 0.0 & 1.4 & $\mathbf{1 . 1}$ \\
\hline
\end{tabular}

A separate analysis of the degree of severity of symptoms caused by arachnid genera that we have previously classified as potentially dangerous (Hauke and Herzig, 2017) showed a profound shift from local to minor symptoms in dangerous spider and a similar but less pronounced shift in dangerous scorpion genera (Table 4).

Table 4. Comparison of the percental distribution of severity of symptoms for non-dangerous versus dangerous arachnids. Data is based on $\mathrm{N}=244$ spider bites and $\mathrm{N}=33$ scorpion stings from non-dangerous and $\mathrm{N}=52$ spider bites and $\mathrm{N}=25$ scorpion stings from dangerous arachnid genera according to our previous classification (Hauke and Herzig, 2017). Incidence rates from $30 \%$ are highlighted in yellow (and in bold from $50 \%$ ).

\begin{tabular}{|l|l|l|l|l|}
\cline { 2 - 5 } \multicolumn{1}{c|}{} & \multicolumn{2}{c|}{ Spiders } & \multicolumn{2}{c|}{ Scorpions } \\
\hline Symptom severity (\%) & Non-dangerous & Dangerous & Non-dangerous & Dangerous \\
\hline Asymptomatic & 6.6 & 0.0 & 9.1 & 0.0 \\
Local & 65.6 & 28.8 & 72.7 & 64.0 \\
Minor & 27.5 & 65.4 & 18.2 & 36.0 \\
Severe & 0.4 & 5.8 & 0.0 & 0.0 \\
\hline
\end{tabular}

For the in-depth analysis of bite/sting symptoms within particular genera, we focused on those symptoms with an incidence rate of at least $30 \%$ in genera with at least 5 case reports (Table 5). Similar to the analysis for all the arachnid exposures (Table 2), the most prominent symptom observed in the analysis of the selected genera was local pain, which ranged from $46.2 \%$ in Avicularia to $100 \%$ in Heteroscodra, Pelinobius and Hottentotta. Symptoms that featured most prominently only in one or a few genera are local bleeding (57.1\% incidence in Pelinobius), paraesthesia $(54.5 \%$ incidence in 
In order to obtain an idea about the severity of the symptoms in the selected arachnid genera, we classified each case into either asymptomatic, local, minor or severe (Table 5). Our results highlight that the majority of all cases were local (in 12 out of 17 genera "local" had the highest incidence rate) followed by minor symptoms (in four out of 17 genera "minor" had the highest incidence rate and one genus [i.e. Hysterocrates] had an equal incidence rate for "local" and "minor"). Asymptomatic cases were recorded only from some genera (seven out of 17 genera) but had an incidence rate of up to $23.1 \%$ for the spider genus Avicularia and 28.6\% for the scorpion genus Pandinus, respectively. Only four severe cases were reported, which were caused by spiders of the genera Poecilotheria (3x) and Pterinochilus (1x) and which resulted in the patient being hospitalized due to unconsciousness and several other systemic symptoms (e.g. nausea/vomiting; Table S4).

Table 5. Analysis of bite and sting symptoms (shaded in blue, in alphabetical order) and distribution of severity of symptoms (shaded in green, Asymp. = asymptomatic, no effects) in arachnid genera with at least 5 case reports. Incidence rates from $30 \%$ are highlighted in yellow (and in bold from $50 \%$ ).

\begin{tabular}{|c|c|c|c|c|c|c|c|c|c|c|c|c|c|c|c|c|c|c|}
\hline & Genus & $\mathrm{N}=$ & Itching & $\begin{array}{l}\text { Local } \\
\text { bleeding }\end{array}$ & $\begin{array}{l}\text { Local } \\
\text { pain }\end{array}$ & $\begin{array}{l}\text { Muscle } \\
\text { cramps }\end{array}$ & Numbness & Paraesthesia & Paralysis & $\begin{array}{l}\text { Puncture } \\
\text { marks }\end{array}$ & $\begin{array}{l}\text { Radiating } \\
\text { pain }\end{array}$ & Redness & Stiffness & Swelling & Asymp. & Local & Minor & Severe \\
\hline \multirow{14}{*}{$\begin{array}{l}\frac{\infty}{d} \\
\frac{0}{0} \\
\frac{0}{2}\end{array}$} & Aphonopelma & 9 & 33.3 & 22.2 & 88.9 & 0.0 & 11.1 & 0.0 & 0.0 & 33.3 & 11.1 & 11.1 & 0.0 & 44.4 & 0.0 & 88.9 & 11.1 & 0.0 \\
\hline & Avicularia & 13 & 38.5 & 15.4 & 46.2 & 7.7 & 0.0 & 15.4 & 7.7 & 15.4 & 0.0 & 30.8 & 7.7 & 15.4 & 23.1 & 76.9 & 0.0 & 0.0 \\
\hline & Brachypelma & 7 & 14.3 & 28.6 & 57.1 & 14.3 & 28.6 & 14.3 & 0.0 & 42.9 & 14.3 & 14.3 & 0.0 & 28.6 & 0.0 & 85.7 & 14.3 & 0.0 \\
\hline & Caribena & 13 & 46.2 & 15.4 & 92.3 & 0.0 & 7.7 & 15.4 & 0.0 & 38.5 & 0.0 & 23.1 & 7.7 & 38.5 & 0.0 & 100.0 & 0.0 & 0.0 \\
\hline & Grammostola & 39 & 38.5 & 20.5 & 79.5 & 5.1 & 2.6 & 10.3 & 0.0 & 28.2 & 0.0 & 12.8 & 5.1 & 38.5 & 7.7 & 79.5 & 12.8 & 0.0 \\
\hline & Haplopelma & 12 & 8.3 & 8.3 & 66.7 & 33.3 & 33.3 & 0.0 & 0.0 & 33.3 & 8.3 & 0.0 & 0.0 & 33.3 & 16.7 & 33.3 & 50.0 & 0.0 \\
\hline & Heteroscodra & 11 & 9.1 & 0.0 & 100.0 & 36.4 & 36.4 & 54.5 & 0.0 & 9.1 & 36.4 & 45.5 & 27.3 & 27.3 & 0.0 & 18.2 & 81.8 & 0.0 \\
\hline & Hysterocrates & 9 & 22.2 & 11.1 & 55.6 & 22.2 & 0.0 & 22.2 & 0.0 & 22.2 & 22.2 & 11.1 & 0.0 & 55.6 & 11.1 & 44.4 & 44.4 & 0.0 \\
\hline & Omothymus & 6 & 0.0 & 16.7 & 83.3 & 0.0 & 16.7 & 0.0 & 33.3 & 33.3 & 16.7 & 50.0 & 50.0 & 33.3 & 0.0 & 66.7 & 33.3 & 0.0 \\
\hline & Pelinobius & 7 & 42.9 & 57.1 & 100.0 & 28.6 & 14.3 & 14.3 & 14.3 & 42.9 & 14.3 & 42.9 & 14.3 & 57.1 & 0.0 & 57.1 & 42.9 & 0.0 \\
\hline & Poecilotheria & 49 & 12.2 & 18.4 & 85.7 & 59.2 & 22.4 & 12.2 & 2.0 & 32.7 & 22.4 & 32.7 & 20.4 & 57.1 & 0.0 & 28.6 & 65.3 & 6.1 \\
\hline & Psalmopoeus & 10 & 30.0 & 0.0 & 90.0 & 10.0 & 30.0 & 10.0 & 0.0 & 20.0 & 10.0 & 20.0 & 20.0 & 40.0 & 0.0 & 70.0 & 30.0 & 0.0 \\
\hline & Pterinochilus & 34 & 5.9 & 5.9 & 91.2 & 44.1 & 23.5 & 5.9 & 0.0 & 26.5 & 23.5 & 11.8 & 14.7 & 55.9 & 5.9 & 35.3 & 55.9 & 2.9 \\
\hline & Tliltocatl & 18 & 11.1 & 16.7 & 50.0 & 5.6 & 5.6 & 5.6 & 0.0 & 33.3 & 0.0 & 33.3 & 11.1 & 33.3 & 11.1 & 83.3 & 5.6 & 0.0 \\
\hline \multirow{3}{*}{ 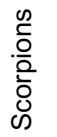 } & Centruroides & 10 & 0.0 & 10.0 & 80.0 & 0.0 & 30.0 & 10.0 & 10.0 & 0.0 & 30.0 & 10.0 & 10.0 & 30.0 & 0.0 & 60.0 & 40.0 & 0.0 \\
\hline & Hottentotta & 5 & 20.0 & 0.0 & 100.0 & 0.0 & 20.0 & 40.0 & 0.0 & 20.0 & 40.0 & 60.0 & 0.0 & 60.0 & 0.0 & 60.0 & 40.0 & 0.0 \\
\hline & Pandinus & 7 & 14.3 & 0.0 & 71.4 & 0.0 & 28.6 & 0.0 & 0.0 & 0.0 & 0.0 & 0.0 & 0.0 & 28.6 & 28.6 & 42.9 & 28.6 & 0.0 \\
\hline
\end{tabular}




\section{Discussion}

The gold standard for assessing the toxicological effects from arachnid bites and stings is to rely on verified bites, which includes the taxonomical identification of the responsible arachnid species as well as the clinical follow-up of the resulting effects (Isbister and White, 2004). Pet spiders and scorpions are typically well identified at least to the genus (often even to the species) level by experts before being distributed in the pet trade, so that pet owners are usually well aware of the correct taxonomic identities of their arachnids (Fuchs et al., 2014). Accordingly, we assumed that the taxonomic identity of the arachnids in our study was correctly identified to the genus level, which we used for our data analysis. By relying on self-reported cases, the symptoms we recorded were mostly described by lay persons instead of medical professionals. Therefore, an objective reporting cannot always be assumed for each case. In order to minimize any reporting bias from less accurate diagnoses, we focused on symptoms with a higher incidence rate and on easy-to-self-diagnose symptoms (e.g. redness, swelling, pain, cramps, nausea). Symptoms that required an accurate measurement or a diagnosis by a clinician (e.g. irregular heartbeat, fever) were not included. Furthermore, it needs to be emphasized that this study focused on the circumstances, under which pet arachnid bites and stings happened, on the taxa being responsible for these incidents and on the scope of potential outcomes. Given that only a minority of bitten/stung humans are seeking medical help, this kind of reporting for the resulting symptoms has to be accepted as an inherent drawback of such kind of examination in order to allow gathering a comprehensive and significant number of cases. In summary, this study was designed to provide the framework for future case reports, which may then focus more deeply on the clinical effects.

Our results reveal some interesting details about sting/bite incidents with arachnid pets. Of those 354 cases recorded in our database, $10.5 \%$ of the pet owners that get bitten or stung required medical assistance and only $1.1 \%$ of all cases were classified as severe. We further noticed that the vast majority of all incidents occurred during deliberate interaction with the pet arachnids, with handling, maintenance, transferring and fleeing during these interactions amounting to $93.2 \%$ of all cases, whereas only $4.3 \%$ were accidentally caused by arachnids that have escaped unseen and $2.5 \%$ of all bites and stings have even been actively induced. In accordance, the hand (85.0\%) and arm (7.5\%) were the body parts most often targeted by arachnids. This implies that by applying the appropriate caution and safety measures (e.g. wearing protective gloves or using long forceps) when interacting with arachnid pets, the majority of all cases could most likely be prevented. The fact that the victims were mainly male is an unsurprising finding. Not only are men known to be more risk-loving, the majority of all arachnid pet owners are apparently male. In case of the Deutsche Arachnologische Gesellschaft e.V. (DeArGe) for example, $82.7 \%$ of all members are men, which nicely reflects their representation among the envenomation victims. Another unsurprising finding is that the offending arachnids were mainly female. Most of the cases were caused by theraphosid spiders and it is well known that female theraphosids have a much longer lifespan than males (Foelix, 2011) and in many cases the females are also larger than males of the same species (Herzig, 2010). Thus, this results in increased prevalence of females among pet arachnids and also in a lower risk of male arachnids causing notable effects.

What our data does not reveal is how big the global arachnid pet scene is and unfortunately there are also no simple ways to determine the global numbers of arachnid pet owners. The world's two largest societies dedicated to pet arachnids, the DeArGe and the British Tarantula Society (BTS), currently have 927 and 507 (paying) / 1113 (registered) members, respectively. However, we assume only a small fraction of all arachnid pet owners are willing to pay annual fees for being members of any of these societies. Apparently, the majority of arachnid enthusiasts obtain their knowledge on the maintenance of arachnid pets in captivity either from popular books or an increasing number is seeking free advice from social media (e.g. Facebook ) or video channels (e.g. YouTube ), respectively. The numbers of subscribers of popular YouTube channels dealing with arachnid pets ranges from 
the tens of thousands (e.g. "birdspidersCH" from Switzerland with 20,400 subscribers) to several hundreds of thousands (e.g. "The Dark Den" from Croatia with 519,000 subscribers). Based on these numbers, it would seem safe to estimate the global numbers of arachnid pet owners to be at least several tens of thousands. Interestingly, when comparing the recorded number of bite and sting cases over the past two decades, we noticed a 55\% decrease from the previous to the current decade. There could be several possible explanations for this observation. The hobby could be in decline, it could be due to a reporting bias (e.g. more people tending to social media such as Facebook or video channels like YouTube while posting reports in online forums, the main source of cases for our present study, is declining) or due to an improved education of arachnid pet owners (e.g. learning from the mistakes of others; more knowledge available about the behavior of arachnid species kept as pets). Monitoring the envenomation incidents over the next decade might provide an answer to this question.

Our data reveal that incidents with pet arachnids are dominated by spiders from the family Theraphosidae (96.3\% of all spider bites, $80.5 \%$ of all arachnid incidents) and scorpions from the families Buthidae and Scorpionidae (totaling $82.7 \%$ of all scorpion stings, $13.6 \%$ of all arachnid incidents). These numbers largely reflect the preference of particular arachnids among the pet owners. However, a few arachnid genera caused a disproportionate number of cases. The spider genera Grammostola, Poecilotheria and Pterinochilus and the scorpion genera Centruroides and Pandinus were responsible for considerably more cases than would have been predicted based on their popularity. One reason for the over-representation of some genera could be that they behave in an unexpected way (e.g. erratic and fast movements), which could be the case for Poecilotheria and Pterinochilus, or that they are less docile than reported in the popular literature, which could be the case for Grammostola and Pandinus. Another explanation could be that a genus is under-represented in the popular literature, which we believe could be the case for Centruroides. Only the spider genus Brachypelma caused considerably fewer bites than would have been expected based on its popularity, which we believe might be due to those spiders rather using their urticating hairs than their venoms for defensive purposes (Battisti et al., 2011).

Only a few of the cases in our study reported outcomes that are considered uncommon for the particular arachnid genus that caused the bites or stings and in some cases it was difficult to assess, whether the mentioned effects are a direct consequence of the arachnid bite/sting or whether they are rather attributable to pre-existing conditions. For example, four cases (unique case numbers 9, 270, 305, and 328, see Supplementary Excel Table) reported breathing difficulties in envenomation victims with pre-existing asthmatic conditions. Whether these symptoms were directly caused by components in the venoms or by increased stress due to the incident is difficult to determine based on the limited data available in these reports. The fact that these symptoms in combination with the pre-existing asthma were reported from a variety of spider (Thrixopelma, Poecilotheria, Pterinochilus) and scorpion (Centruroides) genera would argue against a specific venom component being responsible. One case (unique case 236, see Supplementary Excel Table) that has been classified as severe, which resulted in unconsciousness amongst several other symptoms of the victim, also mentioned that the medications administered by the ambulance staff were not tolerated and might have contributed to the severity of the effects. Another interesting case (unique case 48, see Supplementary Excel Table) was stung twice by the same scorpion species (Pandinus imperator) on two separate incidents. The victim referred to the symptoms after the second time as being more severe, reporting strong pain, breathing difficulties, circulatory problems, and shock-like symptoms. These symptoms are uncommon after stings from Pandinus, which usually cause rather mild symptoms that are characterized by pain, swelling, numbness and itching (Table 5). Allergic reactions to arachnid venoms, unlike for hymenopterans, are rarely reported (Lima Araujo Melo et al., 2019; Srugo et al., 2009). However, some allergens have been described from scorpion venoms (More et al., 2004) and were observed to even exhibit cross-reactivity with hymenopteran allergens (Nugent et al., 2004). Thus, based on the symptoms and the fact that the victim was stung repeatedly in separate incidents by the same species 
of scorpion, a type- 1 hypersensitivity reaction cannot be ruled out as a potential explanation for the more pronounced manifestations following the second sting from Pandinus in unique case number 48. However, without more detailed clinical data on this case, a conclusive diagnosis is impossible.

The most prominent symptom caused by spider bites and scorpion stings in our database was local pain, being observed in $80.5 \%$ of all cases. This finding supports many previous reports of local pain being the most prominent symptom after arachnid bites or stings (Bucaretchi et al., 2000; Bucaretchi et al., 2014; Isbister and Fan, 2011). Furthermore, pain-inducing venom components are a well-established defense mechanism for arachnids (Bohlen et al., 2010; Inceoglu et al., 2003; Osteen et al., 2016; Siemens et al., 2006). Other prominent symptoms particularly caused by spider bites were muscle cramps, local bleeding, puncture marks, nausea/vomiting, generalised pain, stiffness, itching and redness. On the other hand, paraesthesia, numbness and radiating pain were more prominently observed after scorpion stings. A similar range of symptoms was also described from bites and stings by Australian arachnids with pain being the predominant symptom caused by all arachnids and paraesthesia and numbness exhibiting a higher incidence rate in scorpions (Isbister and Gray, 2002, 2004; Isbister et al., 2003b). However, comparing the actual percentages for the incidence rates that we observed with other published results is hampered by differences in the diversity and geographical origin of the arachnids involved in these incidents. The published literature on clinical effects is heavily biased towards medically important arachnids. In contrast, our data on spiders includes three cases (out of 296) from medically important spiders and is otherwise clearly focused on the medically less important theraphosids, accounting for $96.3 \%$ of all spider bites. Previous clinical evidence indicates that Australian and Brazilian theraphosid bites only caused mild symptoms with pain being the most prevalent effect (Isbister et al., 2003a; Lucas et al., 1994). The theraphosids included in our study originated from various parts across their natural distribution range including the Americas, Africa and Asia. Geographic differences of the effects caused by theraphosid venoms have already been documented with respect to certain African and Asian theraphosids being implied to have a higher neurotoxicity in mice (Escoubas and Rash, 2004). Our data supports that some African and Asian theraphosid genera such as Heteroscodra, Pelinobius, Poecilotheria and Pterinochilus predominantly caused minor effects, whereas local effects were predominant after bites by the New World genera Aphonopelma, Avicularia, Caribena, Grammostola, Psalmopoeus and Tliltocatl. However, it is yet too early to draw a general conclusion about potential geographic variations in the severity of symptoms caused by theraphosid bites as this should be examined in a more detailed way by taking both the geographic origin as well as the phylogenetic relationship into account. And other factors such as the venom amount might also play a crucial role.

Visual signs at the bite/sting site (such as puncture marks, bleeding, swelling, redness) were more common after spider bites than after scorpion stings. This could be attributed to the relatively large fang size of theraphosid spiders (Isbister and Gray, 2004). One symptom that was only caused by spider bites and not by scorpion stings are cramps of skeletal muscles. In particular the genus Poecilotheria caused an incidence rate of $59.2 \%$ of muscle cramps, which correlates well with the $58 \%$ reported by a previous study (Fuchs et al., 2014). Our data therefore further adds to the evidence of muscle cramps being caused by Poecilotheria venoms in vertebrates such as humans (Ahmed et al., 2009; Fuchs et al., 2014) or mice (Andreev-Andrievskiy et al., 2017). Other theraphosid genera that exhibited a high incidence rate of muscle cramps include Haplopelma (33.3\%), Heteroscodra (36.4\%) and Pterinochilus (44.1\%), with the latter two genera also previously being reported for inducing muscle cramps in humans (Ahmed et al., 2009; Fuchs et al., 2018). In some of our cases, those muscle cramps were reported to be long-lasting, sometimes occurring over periods of several weeks or even months. While previous studies have classified muscle cramps as a severe symptom (Ahmed et al., 2009), we do not share this view for two reasons. Firstly, the sole presence of muscle cramps does not represent a reliable indicator for the severeness of an arachnid envenomation, as in some cases, the muscle cramps were explicitly described as mild or locally restricted, whereas in others they were 
experienced as extraordinary painful and debilitating. Secondly, skeletal muscle cramps are usually not life-threatening, unless they affect the diaphragm muscle to interfere with breathing.

When specifically comparing incidents from those arachnid genera that we have previously classified as non-dangerous to those considered potentially dangerous (Hauke and Herzig, 2017), we found a shift from local to minor symptoms in spiders and a similar but less pronounced shift in scorpions. This implies that incidents with potentially dangerous arachnid pets do not necessarily result in severe consequences, with only $3.9 \%$ of the recorded incidents (i.e. three severe cases amongst all 77 bites/stings) from dangerous arachnids causing severe symptoms. Notably, we gathered several incidents from arachnids that are historically considered being of medical importance in their respective countries of origins, namely from spiders of the genera Latrodectus and Phoneutria and scorpions of the genera Androctonus, Centruroides, Hottentotta, Leiurus, Olivierus, Parabuthus, and Tityus (Isbister and Fan, 2011; Ward et al., 2018). However, none of these were involved in a severe envenomation in this study. Conversely, all four cases we classified as severe were caused by the theraphosid genera Poecilotheria and Pterinochilus, with theraphosids being only considered of minor medical importance in their countries of origins (Isbister et al., 2003a; Lucas et al., 1994).

When using a risk matrix to perform an assessment for the risk associated with venomous arachnid pets, the overall risk is determined by two factors, i.e. the likelihood and the consequence. The likelihood of being bitten or stung by an arachnid is obviously increased, if they are kept at home as pets. We recorded 354 incidents with pet arachnids, with most of them occurring in the last two decades. On the background of tens of thousands of assumed arachnid pet owners globally, the recorded case numbers appear low, although we have to assume that many inconsequential incidents with pet arachnids have gone unnoticed if the pet owners did not consider a lack of symptoms worth reporting. Nevertheless, the overall likelihood of being bitten or stung by an arachnid pet can be considered low and there are a number of simple measures that arachnid pet owners can implement to further reduce this likelihood. These measures for example include keeping arachnids in tight enclosures to prevent accidental escape, using sturdy gloves or long forceps for any interaction with the arachnids if required for maintenance purposes, and avoiding any direct physical contact. Our data imply that $\sim 90 \%$ of all cases were due to a lack of due care when interacting with the arachnids and are therefore considered preventable. When it comes to the consequences of the arachnid bites and stings, our data show that only four of the 354 cases $(=1.1 \%)$ were classified as severe. In other words, about $99 \%$ of all cases showed either local, minor or no symptoms at all. Therefore, the typical consequences (symptoms) of arachnid bites and stings can be regarded as mild. Combining a low likelihood of incidents with the overwhelmingly mild symptoms of these bites and stings leads to a low overall risk rating associated with arachnid pet ownership. Other hobbies and leisure activities such as beekeeping or sports are associated with more severe outcomes. For example, over a ten year period from 2009-2018, there were more than 16 annual deaths registered due to honeybees and other hymenopterans according to statistical data from Germany and almost 50 annual deaths in the USA from 1991-2001 (Langley, 2005). Sports or drowning related accidents from 2009-2018 accounted for an annual average of 196 and 17 deaths, respectively, in Germany alone. Any recreational activity is associated with specific risks and judging from the low overall risk associated with keeping arachnids as pets, the introduction of legislative restrictions on this hobby seems disproportionate. However, providing guidelines to arachnid enthusiasts for improving due care when interacting with their arachnid pets could be helpful in preventing most incidents. As pet arachnids continue to be an important source of venoms and toxins used for research to benefit humanity (Herzig et al., 2020; Osteen et al., 2016), imposing unsubstantiated regulatory measures could even negatively impact the progress of research as evidenced by research on venomous cone snails (Bjorn-Yoshimoto et al., 2020).

\section{Conclusions}


In the present study, we have compiled and assessed 354 self-reported cases of bites and stings from pet arachnids. These cases resulted mostly in local or minor symptoms and only $10.5 \%$ of the victims sought professional medical assistance. Furthermore, about $90 \%$ of these cases might have been avoidable by applying due care when interacting with the arachnid and only $1.1 \%$ of all cases were classified as severe with no recorded fatalities. By performing a risk assessment that is based on the analysis of all cases in our database, we conclude that the overall risk associated with arachnid pet ownership is low and that this hobby therefore bears a lower risk than many other more common recreational activities. In general, we encourage the establishment of guidelines that provide information and rules for the keeping and handling of "exotic pets" (not limited to arachnids) to lower any potential risks for both animals and owners. At this stage, however, we do neither see any need nor benefit in introducing legislation to stricter regulate or even prohibit arachnid pet ownership.

Supplementary Materials: The following data are available as E-component / supplementary material linked to this article: Supplementary Material, Supplementary Excel File, Questionnaire pet arachnid envenomationsEnglish, Questionnaire pet arachnid envenomations-German.

Author Contributions: Conceptualization; methodology; formal analysis; data curation; writing - original draft preparation; writing - review and editing, T.H. and V.H.; project administration, V.H. All authors have read and agreed to the published version of the manuscript.

Funding: V.H. is funded by a Future Fellowship from the Australian Research Council (FT190100482).

Acknowledgments: We would like to thank Geoffrey K. Isbister for helpful comments on the design of the questionnaire and on the manuscript. We further like to thank the DeArGe (and in particular Tim Lüddecke for extracting the member data), the BTS (and in particular Ray Hale and Mike Strick for extracting the member data) and the Natur-und-Tier-Verlag for distributing our questionnaire, and all pet owners who contributed by filling out and returning the questionnaire or by providing their envenomation reports in any of the other print or online media.

\section{References}

Aachener Zeitung, 2019. https://www.aachener-zeitung.de/nrw-region/giftschlange-in-herne-wurde-gefundenund-eingefangen aid-45481207 (accessed 2/9/2020).

Aachener Zeitung, 2020. https://www.aachener-zeitung.de/nrw-region/verfassungsbedenken-gegen-neuesgifttiergesetz aid-49617349 (accessed 2/9/2020).

Ahmed, N., Pinkham, M., Warrell, D.A., 2009. Symptom in search of a toxin: muscle spasms following bites by Old World tarantula spiders (Lampropelma nigerrimum, Pterinochilus murinus, Poecilotheria regalis) with review. Qjm-Int. J. Med. 102, 851-857.

Andreev-Andrievskiy, A., Popova, A., Lagereva, E., Osipov, D., Berkut, A., Grishin, E., Vassilevski, A., 2017. Pharmacological analysis of Poecilotheria spider venoms in mice provides clues for human treatment. Toxicon 138, 59-67.

Angelfire, http://www.angelfire.com/my/vogelspinnen/bitereports.html (accessed on 19/10/2020).

Arachnoboards, https://arachnoboards.com/ (accessed on 2/9/2020).

Arachnophilia, http://www.arachnophilia.de/forum/ (accessed on 2/9/2020).

Battisti, A., Holm, G., Fagrell, B., Larsson, S., 2011. Urticating hairs in arthropods: their nature and medical significance. Annu. Rev. Entomol. 56, 203-220.

Bayrische Staatskanzlei, 2015.

https://www.gesetzebayern.de/(X(1)S(2bkyjovcongzv4gyn1jgac0x))/Content/Document/BayVwV96517137? AspxAutoDetectCookieSupport=1 (accessed 2/9/2020).

Bibic, L., Herzig, V., King, G.F., Stokes, L., 2019. Development of high-throughput fluorescent-based screens to accelerate discovery of P2X inhibitors from animal venoms. J. Nat. Prod. 82, 2559-2567. 
birdspidersCH, https://www.youtube.com/c/birdspidersCH/featured (accessed 2/9/2020).

Bjorn-Yoshimoto, W.E., Ramiro, I.B.L., Yandell, M., McIntosh, J.M., Olivera, B.M., Ellgaard, L., Safavi-Hemami, H., 2020. Curses or cures: a review of the numerous benefits versus the biosecurity concerns of conotoxin research. Biomedicines 8, 235.

Bohlen, C.J., Priel, A., Zhou, S., King, D., Siemens, J., Julius, D., 2010. A bivalent tarantula toxin activates the capsaicin receptor, TRPV1, by targeting the outer pore domain. Cell 141, 834-845.

BTS homepage, http://www.thebts.co.uk/selenocosmia.htm (accessed on 19/10/2020).

Bucaretchi, F., Deus Reinaldo, C.R., Hyslop, S., Madureira, P.R., De Capitani, E.M., Vieira, R.J., 2000. A clinicoepidemiological study of bites by spiders of the genus Phoneutria. Rev. Inst. Med. Trop. Sao Paulo 42, 17-21.

Bucaretchi, F., Fernandes, L.C., Fernandes, C.B., Branco, M.M., Prado, C.C., Vieira, R.J., De Capitani, E.M., Hyslop, S., 2014. Clinical consequences of Tityus bahiensis and Tityus serrulatus scorpion stings in the region of Campinas, southeastern Brazil. Toxicon 89, 17-25.

Das Informationssystem der Gesundheitsberichterstattung des Bundes,

http://www.gbebund.de/gbe10/pkg isgbe5.prc isgbe?p uid=gast\&p aid=0\&p sprache=D (accessed 2/9/2020).

Escoubas, P., Rash, L., 2004. Tarantulas: eight-legged pharmacists and combinational chemists. Toxicon 43, 555574.

Facebook, https://www.facebook.com/ (accessed 2/9/2020).

Foelix, R., 2011. Biology of Spiders. Oxford University Press, New York, USA.

Foelix, R., Rast, B., Erb, B., 2009. Palpal urticating hairs in the tarantula Ephebopus: fine structure and mechanism of release. J. Arachnol. 37, 292-298.

Foelix, R.F., Rast, B., Peattie, A.M., 2012. Silk secretion from tarantula feet revisited: alleged spigots are probably chemoreceptors. J. Exp. Biol. 215, 1084-1089.

Foley, S., Lueddecke, T., Cheng, D.Q., Krehenwinkel, H., Kunzel, S., Longhorn, S.J., Wendt, I., von Wirth, V., Taenzler, R., Vences, M., Piel, W.H., 2019. Tarantula phylogenomics: A robust phylogeny of deep theraphosid clades inferred from transcriptome data sheds light on the prickly issue of urticating setae evolution. Mol. Phylogenet. Evol. 140, 106573.

Fuchs, J., Martin, N.C., Rauber-Luthy, C., 2018. A verified bite by Heteroscodra maculata (Togo starburst or ornamental baboon tarantula) resulting in long-lasting muscle cramps. Clin. Toxicol. 56, 675-676.

Fuchs, J., von Dechend, M., Mordasini, R., Ceschi, A., Nentwig, W., 2014. A verified spider bite and a review of the literature confirm Indian ornamental tree spiders (Poecilotheria species) as underestimated theraphosids of medical importance. Toxicon 77, 73-77.

Fukushima, C.S., Cardoso, P., Bertani, R., 2020. Description of the male of the critically endangered tarantula Typhochlaena curumim Bertani, 2012 (Araneae, Theraphosidae), with comments on tarantula trade and conservation. Zookeys 938, 125-136.

Hauke, T.J., Herzig, V., 2017. Dangerous arachnids-Fake news or reality? Toxicon 138, 173-183.

Herzig, V., 2010. Ontogenesis, gender, and molting influence the venom yield in the spider Coremiocnemis tropix (Araneae, Theraphosidae). J. Venom Res. 1, 76-83.

Herzig, V., Cristofori-Armstrong, B., Israel, M.R., Nixon, S.A., Vetter, I., King, G.F., 2020. Animal toxins - Nature's evolutionary-refined toolkit for basic research and drug discovery. Biochem. Pharmacol., 114096.

Huesser, M., 2018. A first phylogenetic analysis reveals a new arboreal tarantula genus from South America with description of a new species and two new species of Tapinauchenius Ausserer, 1871 (Araneae, Mygalomorphae, Theraphosidae). Zookeys 784, 59-93. 
Inceoglu, B., Lango, J., Jing, J., Chen, L., Doymaz, F., Pessah, I.N., Hammock, B.D., 2003. One scorpion, two venoms: prevenom of Parabuthus transvaalicus acts as an alternative type of venom with distinct mechanism of action. Proc. Natl. Acad. Sci. USA 100, 922-927.

Isbister, G.K., Fan, H.W., 2011. Spider bite. Lancet 378, 2039-2047.

Isbister, G.K., Gray, M.R., 2002. A prospective study of 750 definite spider bites, with expert spider identification. Q. J. Med. 95, 723-731.

Isbister, G.K., Gray, M.R., 2004. Bites by Australian mygalomorph spiders (Araneae, Mygalomorphae), including funnel-web spiders (Atracinae) and mouse spiders (Actinopodidae: Missulena spp). Toxicon 43, 133-140.

Isbister, G.K., Seymour, J.E., Gray, M.R., Raven, R.J., 2003a. Bites by spiders of the family Theraphosidae in humans and canines. Toxicon 41, 519-524.

Isbister, G.K., Volschenk, E.S., Balit, C.R., Harvey, M.S., 2003b. Australian scorpion stings: a prospective study of definite stings. Toxicon 41, 877-883.

Isbister, G.K., White, J., 2004. Clinical consequences of spider bites: recent advances in our understanding. Toxicon 43, 477-492.

Khattabi, A., Soulaymani-Bencheikh, R., Achour, S., Salmi, L.R., Scorpion Consensus Expert Group, 2011. Classification of clinical consequences of scorpion stings: consensus development. Trans. R. Soc. Trop. Med. Hyg. 105, 364-369.

Klint, J.K., Smith, J.J., Vetter, I., Rupasinghe, D.B., Er, S.Y., Senff, S., Herzig, V., Mobli, M., Lewis, R.J., Bosmans, F., King, G.F., 2015. Seven novel modulators of the analgesic target Nav1.7 uncovered using a highthroughput venom-based discovery approach. Br. J. Pharmacol. 172, 2445-2458.

Kroes, T., Maerklin, T., 2014. Erfahrungsbericht ueber das erste Poecilotheria Auswilderungsprogramm im April und Dezember 2013 in Sri Lanka. Arachne 19, 28-39.

Langley, R.L., 2005. Animal-related fatalities in the United States-an update. Wilderness Environ. Med. 16, 6774.

Law, Y.H., 2019. New tarantula highlights illegal trade in spiders. Science 363, 914-915.

Lima Araujo Melo, I.M., Dias Ramalho, R., Vieira Bezerra, M.M., de Oliveira Filho, I.E., Roberto Medeiros, C., da Costa Gadelha, M.A., Pereira de Oliveira Pardal, P., 2019. Fatal anaphylaxis to Jaguajir rochae (Borelli, 1910) (Scorpiones, Buthidae) in Brazil: a case report. Rev. Patol. Trop. 48, 187-194.

Lucas, S.M., Da Silva, P.I., Jr., Bertani, R., Cardoso, J.L.C., 1994. Mygalomorph spider bites: A report on 91 cases in the state of Sao Paulo, Brazil. Toxicon 32, 1211-1215.

Lueddecke, T., Krehenwinkel, H., Canning, G., Glaw, F., Longhorn, S.J., Taenzler, R., Wendt, I., Vences, M., 2018. Discovering the silk road: Nuclear and mitochondrial sequence data resolve the phylogenetic relationships among theraphosid spider subfamilies. Mol. Phylogenet. Evol. 119, 63-70.

Mammola, S., Nanni, V., Pantini, P., Isaia, M., 2020. Media framing of spiders may exacerbate arachnophobic sentiments. People and Nature, 1-13.

Montemor, V.M., West, R.C., Zamani, A., Moradmand, M., von Wirth, V., Wendt, I., Huber, S., Guadanucci, J.P.L., 2020. Taxonomy of the genus Ischnocolus in the Middle East, with description of a new species from Oman and Iran (Araneae: Theraphosidae). Zool. Middle East 66, 76-90.

More, D., Nugent, J., Hagan, L., Demain, J., Schwertner, H., Whisman, B., Freeman, T., 2004. Identification of allergens in the venom of the common striped scorpion. Ann. Allergy Asthma Immunol. 93, 493-498.

Nugent, J.S., More, D.R., Hagan, L.L., Demain, J.G., Whisman, B.A., Freeman, T.M., 2004. Cross-reactivity between allergens in the venom of the common striped scorpion and the imported fire ant. J. Allergy Clin. Immunol. 114, 383-386. 
540 Nunn, S.C., West, R.C., von Wirth, V., 2016. A revision of the selenocosmiine tarantula genus Phlogiellus Pocock 5411897 (Araneae: Theraphosidae), with description of 4 new species. Int. J. Zool., 1-54.

542 Osteen, J.D., Herzig, V., Gilchrist, J., Emrick, J.J., Zhang, C., Wang, X., Castro, J., Garcia-Caraballo, S., Grundy, 543 L., Rychkov, G.Y., Weyer, A.D., Dekan, Z., Undheim, E.A., Alewood, P., Stucky, C.L., Brierley, S.M., 544 Basbaum, A.I., Bosmans, F., King, G.F., Julius, D., 2016. Selective spider toxins reveal a role for the Nav1.1 545 channel in mechanical pain. Nature 534, 494-499.

546 Parlamento Italiano, 2003. https://www.camera.it/parlam/leggi/032131.htm (accessed 10/9/2020).

547 Poeci1, https://poeci1.de/poecilotheria/gift/ (accessed on 19/10/2020).

548 Regierungspräsidium Kassel, 2007. https://rp-kassel.hessen.de/umwelt-natur/naturschutz/artenschutz/private549 haltung-gef\%C3\%A4hrlicher-wildtiere (accessed 2/9/2020).

550 Reptilesworld, https://reptilesworld.de.tl/Vogelspinnenbisse-Betroffene-berichten.htm (accessed on 551 19/10/2020).

Siemens, J., Zhou, S., Piskorowski, R., Nikai, T., Lumpkin, E.A., Basbaum, A.I., King, D., Julius, D., 2006. Spider toxins activate the capsaicin receptor to produce inflammatory pain. Nature 444, 208-212.

SKF - Schattenjaeger im Terrarium, https://www.skorpionforum.com/ (accessed 2/9/2020).

555 SkorpionForum, https://scorpionforum.darkbb.com/ (accessed 2/9/2020).

Srugo, I., Aroch, I., Cruchim, Y., 2009. Anaphylactic reaction to a spider (Chaetopelma aegyptiaca) bite in a dog. Israel J. Vet. Med. 64.

558 The Arachnoholic, https://thearachnoholic.wixsite.com/arachnoholic/arachnoholic-news (accessed 2/9/2020).

559 The Dark Den, https://www.youtube.com/c/TheDarkDen/featuredv (accessed 2/9/2020).

560 UK Government, 1976. https://www.legislation.gov.uk/ukpga/1976/38 (accessed 2/9/2020).

561 Vogelspinnenstammtisch Schweiz, https://vogelspinnenforum.ch/ (accessed 2/9/2020).

562 Ward, M.J., Ellsworth, S.A., Nystrom, G.S., 2018. A global accounting of medically significant scorpions: 563 Epidemiology, major toxins, and comparative resources in harmless counterparts. Toxicon 151, 137-155.

564 YouTube, https://www.youtube.com/ (accessed 2/9/2020). 